\title{
Playing the Game: a Comparison of International Actors in Real Estate Development in Modderfontein, Johannesburg and London's Royal Docks
}

\begin{abstract}
In highly internationalised cities, real estate developers must learn to negotiate global-local tensions to territoralise their work and secure planning permission. This paper examines how they do this and positions itself at the meeting point of research on policy mobility and real estate. Developers have been shown to be co-coordinators of development processes, and one of many agents who facilitate the global flow and production of urban spaces and ideas. In these endeavours local knowledge is important yet developers remain interested in sites beyond their home city. This paper questions what strategies developers utilise to become co-ordinating forces in new cities, a pertinent issue because increasingly urban actors position themselves as 'global' or beyond a geographically circumscribed space.
\end{abstract}

Based on 60 interviews across London's Royal Docks and Johannesburg's Modderfontein, this paper argues that to work in a new location, developers and their consultants must utilise local knowledge, highlighting three specific strategies: (1) on-boarding local political actors; (2) hiring individuals who primarily work in the city and (3) becoming part of 'the club'. These illustrate the ways developers localise themselves, 'learning to play the game', and evidence the consequences for where and how urban politics happens. Ultimately, this paper argues that at the heart of internationalised urban environments there are transnational networks which are becoming sites of urban politics where assemblages of actors are formed that make the global movement of urban ideas possible.

\section{Keywords}

Real Estate Developers, London, Johannesburg, Comparative Urbanism

\section{Highlights}

- Global actors must find a way to embed themselves in local real estate networks in order to secure planning permission

- Local politics dictate the institutional settings within which real estate developers must act

- Real estate developers are shown to adopt a club like mentality which can be joined (by international firms) through the hiring or partnering with local firms 


\section{Introduction}

Sat in the office of one of London's most prominent urban consultancies in early 2017, I explained to an engineer working on the site I was researching in east London the value of comparative approaches, learning from elsewhere, and my decision to compare London's Royal Docks with Modderfontein in Johannesburg. The engineer, who had a British accent and extensive experience leading core teams in the consultancy turned to me and explained that there was no need to go into detail about Modderfontein because he had worked on that site, for the developers in question, during the time period I was looking at. This shared London-Johannesburg experience was a bonding moment for us, but also a chance to reflect on how comparison works beyond the academy - why was I so surprised that a leading consultant had chosen to work on the same project half way round the world as me? How had he picked that site - or rather, how had the developers on the site picked him? And how did he find working there - what was it like to be a global consultant? The role of global consultancies is not new, yet the specific mechanisms and approaches adopted by the private sector when they try to develop real estate in new cities remains relatively unexamined. Using this moment and the subsequent discussion as a starting point, this paper seeks to question how developers and their consultants learn local practices in places they are less familiar with.

As the interview continued and he began to describe his job he positioned himself and his team as distinctly 'global', demonstrating the way some urban actors attempt to transcend global-local dynamics and act 'above' such categories. In this manner they are key in circulating ideas and policies across the world, but how they do this and the extent to which their actions in less familiar places are effective (in terms of securing finance, planning permission or designing an appropriate scheme) depends on their capacity to interact in very specific local situations. These actors contribute to increasingly internationalised urban processes where key stakeholders take on decisionmaking roles beyond their home city, advising or consulting in new places. That said, despite this tendency towards globalisation it is not possible to say real estate markets are merely all becoming 'mature' (de Magalhães, 2008), they exist as distinctly different places which are historically contingent and hyper contextualised. As this comparison across sites in London and Johannesburg demonstrates, global actors can utilise specific mechanisms to deal with this localism and ensure they are effective in their job whilst maintaining their 'global' positioning.

This paper draws on research across two sites - Modderfontein in Johannesburg and the Royal Docks in London - to respond to the call to pay greater attention to real estate developers (Coiacetto, 2001), whilst adopting a comparative approach (Robinson, 2006; Robinson, 2011). It shows the 
interaction between global and local forces - actors, politics, development processes - in the preplanning decision stage of the developments. In doing so it seeks to build on early research on developers which tended to depict real estate actors as individuals for econometric analysis (Bentick and Pogue, 1988; Ellson and Roberts, 1983; Henderson and Mitra, 1996) or agents of a neoliberalised world (c.f Fainstein, 2001). Since, as their role in urban decision making processes increases, especially when it comes to selecting financing models, mobilising specific architectural forms, and engaging in public consultation activities, to capture more elements of the decision-making process, their organisational structure needs to be analysed to better understand their true role in the urban environment and the consequences of their actions. Whilst there has been renewed attention to real estate developers in recent research on financialisation (c.f. Sanfelici and Halbert, 2016; Crosby and Henneberry, 2016; Christophers, 2015; Rouanet and Halbert, 2016; Aalbers, 2017), highlighting the complexity of the private sector in urban settings and its relationship with finance often from elsewhere, the specific role of developers as part of global idea mobility is relatively underdeveloped.

This paper aims to bring together research on real estate development processes and financialisation, with work on policy mobility to address the strategies used by those from the private sector involved in the global flow of urban ideas. In doing so it seeks to answer: how are international components of real estate developers effective in securing planning permission in highly internationalised yet hyper locally-contextualised urban environments? This is done through the cases of Modderfontein in Johannesburg and the Royal Docks in London to show how, in order to operate effectively in new places, international or transnational actors must do the following: (1) on-board local politicians, (2) hire individuals or partners from the city (3) find a way to integrate themselves in local culture. In these ways the developer and their networks learn to play the game of the city's real estate processes.

In both cases development had been happening, or trying to happen, for a long time. The sites are both substantial in the context of their cities and the projects put forward by developers are futuristic visions based on world-city dreaming (Roy and Ong, 2011). The developer in Johannesburg wanted to make Modderfontein into the 'Manhattan of Africa', building high-rise, high-density glass towers which stand in contrast with the dominant low-density, sprawling nature of much of the wider city environment. In the Docks, one developer proposed an Asian business park, a destination for asian businesses in London, which was depicted as 'selling off the silverware' by local media outlets; whilst another wanted to a build a 'brand destination', a concept the public struggled to understand (LDN_Architect, 2017). In both locations the developers were being ambitious and so bringing in the best teams was seen as essential for translating their visions to buildings. However, 
"what starts as chaos, ends as chaos" (JBG_Planner, 2017) if there is "paralysis analysis" on the part of the developer (JBG_Manager, 2017) and a failure to engage with more salient local issues which cannot be understood just through 'objective' data. There is a need to understand the soft power decisions and how best to navigate these, and in the case of international actors it becomes essential for the developer to find mechanisms through which any local tensions or 'ways of doing' can be better understood and incorporated into their approach.

The second section of this paper addresses policy mobility research and reflects on how this can be adapted to focus on people rather than policy, and the private rather than public sector. The third section develops this focus on the private sector and examines existing research on real estate developers and their role as co-ordinating forces capable of straddling various roles, to question what they do and inform research on how they do it. The fourth section presents case overviews of Modderfontein and the Royal Docks and methods. The results on the different approaches adopted are then used to illustrate the relative merits of each in the fifth section. The paper concludes with a discussion showing how knowledge from another location is not enough to be successful elsewhere, rather it is essential developers, when selecting consultants and approaches, consider local context. In highlighting this, the way developers localise themselves and learn to play the local political game becomes evident, demonstrating the territorialised nature of urban politics.

\section{Global Flows of Ideas}

A globalised world requires analysis which engages with the relationship between 'global' and 'local' forces, people and ideas, especially in an urban environment (Robin and Brill, 2018; Robin this issue). Existing research on this in an urban context primarily focuses on the movement of money or policy, and the role of people who bring an idea to their home city. The bulk of this literature builds on an understanding that cities are produced and produce global relational geographies (Massey, 2005), and shows the importance of intermediary actors or gatekeepers in global flows of policy (Healey, 2013). In doing so this research highlights the necessity of research which questions who relocates policy and how. Such an actor orientated approach has highlighted how individuals involved in these processes are vital components in translating and moving policies through mundane actions (Stone, 2004; Larner, 2003). In learning from one place and successfully replicating a policy in their home cities, officials can become 'experts' (McCann, 2008) and a vital part of the global flow of information. 
Policy mobility research has been particularly enlightening in showing how individuals involved in globalised urban settings position themselves, especially research which has directed analysis towards political figures (Rapoport and Hult, 2017). Consequently in following specific policies through a political lens, methodologically, this body of literature traces the people either in their endeavours to learn from elsewhere (see McCann, 2008) or to take their policy to a new place (see Wood, 2014), with the policy remaining the focal point of engagement. Challenging this and responding to Stone's (2004) call for greater attention to people beyond the public sector since increasingly the role of facilitator or mover of policy is fulfilled by non-politicians (Stone, 2004; Bok and Coe, 2017), Rapaport and Hult (2017) illustrate the importance of private sector organisations in the movement of 'norms'. Their research illustrates how, in the context of broader ideas or norms about the urban, rather than a specific policy, it is necessary to question who are experts and how they operate in a way which straddles the global-local binary. Taking this further, re-orientating discussion away from the idea and making actors the central point of analysis facilitates a greater understanding of individual rationalities in different situations. This is particularly applicable in the study of megaprojects, where the role of experts is less about specific policy copycatting and instead more holistic or as part of a marketing exercise (ibid.). Importantly such an approach also reorientates what is traced and in which direction; rather than considering the way actors seek out new ideas from elsewhere and return to their home with them, it necessitates addressing actors from another location 'arriving'. In turn, following the post-structuralist approach of Larner and Laurie (2010), this draws attention towards the private sector and questions wider constraints, strategies and approaches adopted in the moving of people rather than the translation of an idea.

The travelling of and subsequent success (or not) of an overarching approach for development is therefore less about how appropriate an idea is, and more about whether the actors bringing the idea from elsewhere can convince locals of its worth. Analysing this must address assemblages which straddle the public-private sector divide (Prince, 2014) and the way globally positioned individuals and organisations play an essential role (Stone, 2004), especially in an increasingly privatised world (ibid.). Individuals within urban development are evidently capable of being 'successful' elsewhere, partly because many are natural cosmopolitans (Larner and Laurie, 2010) who use their social capital to act on a global stage. What remains relatively under analysed is how individuals who are not traditionally situated in a certain city learn to operate there? Such a question responds to McCann and Ward's (2012) call for a more wide-reaching conversation about mobilities and the embodied practices through which mobility actually occurs (McCann, 2011). This is further complicated when this movement is considered topologically not topographically (Prince, 2017; Robinson, 2016; Allen, 2016), where the travelling of ideas is less about making locations more connected and instead seen as acts folded into one another through emulation and a morphing of 
power (Prince, 2017). The globally entrepreneurial consultant who is, or must find the capacity to be, capable of embedding themselves in local networks and addressing dynamic situations as they bring ideas from other locations. The question this raises is how global actors learn the most appropriate strategy for a new location?

\section{Understanding Real Estate Developers' Roles in the Global Flow of Information}

Real estate developers have become part of the network of global ideas about urban form, which morphs and alters as it reaches specific locations (Robin and Brill, 2018). Their own network, comprised of developers and consultants (Robin, this issue) has traditionally been addressed in academia through urban planning and development models which highlight the breadth of processes and people involved. In recognising a range of roles development models offer a starting point for questioning how global actors create assemblages locally. It is not the purpose of this paper to address the relative merits of the different models, this has been done effectively elsewhere (see for example Gore and Nicholson, 1991; Healey, 1991; Guy and Henneberry, 2000). However, it is worth noting that such models largely exist as snapshots of what can happen from a normative position and are often derived from economics, such that they are reductive and ignore personalities concealed within them (Guy and Harris, 1997; Guy and Henneberry, 2000; Healey, 1991), limiting their applicability to a more post-structuralist account seeking to understand the importance of interpersonal relationships (see for example Larner and Laurie, 2010). That said, they offer a crucial learning for when questioning how individuals learn to operate elsewhere - the perception of the developer as the principle actor (Goodchild and Munton, 1986) (emphasis added).

More recent research has developed on these early illustrations of developers' roles to show how developers can co-ordinate a multiplicity of motivations and actions (Brown, 2015), assembling people (Fainstein, 2001; Weinstein, 2014) and documents (Robin, this issue), utilising informal relationships to do so. In this research developers have been shown to demonstrably stitch together fragmented institutional settings, often straddling the public-private sector divide (Weinstein, 2011) and whilst the situation they orchestrate cannot be described as 'one man handled' (Weinstein, 2014: p.23), the significance of developers cannot be underestimated. They are entrepreneurial forces capable of navigating political tensions (Fainstein, 2001), even in locations outside their home city (Weinstein, 2014). However, the means by which they become aware of the subtleties of local political situations and the culture in which they must become embedded is relatively unquestioned especially the specificities of the strategies and mechanisms deployed. 
The approaches and specific actions of the private sector in terms of creating urban form has emerged in the context of financialisation (see Aalbers, 2017; Halbert and Attuyer, 2016), where recent research has shown how in some cases developers become intermediaries capable of landing foreign finance and information in a locally contextualised manner. This research demonstrates how, despite the relative centrality of developers in private sector governance, when looking at internationalised settings the role of local firms (Wood, 2004) and connectedness to the local environment (Fainstein, 2001) is essential, especially consideration of intimate knowledge of the political context. Specifically developers have been shown to utilise their social capital to circulate information about a city's market (Halbert and Rouanet, 2014), creating networks of interactions based on their experience in a city and working with local politicians, which are not geographically circumscribed (ibid.). Rather these networks transcend state boundaries and blur any distinction between global and local, and speaking back to the importance of local information, in the context of global assemblages, it's vital to recognise that these transcalar networks do not happen in isolation, rather institutional settings including national policy are significantly influential (Stone, 2004; Halbert and Rouanet, 2014; Weinstein and Baliga, this issue). Building on this, in the context of questioning the role of international actors, it's necessary to recognise the "transcalar nature of urban development as it sees cities as simultaneously drawing influences and extending influences to the further corners of globe" (Halbert and Rutherford, 2010). Therefore research must be attendant to multiple levels of politics, and how global and local actors are part of this multi-level politicised setting.

\section{Methodology and Case Overviews}

This research is based on 60 in-depth interviews with professionals involved in two large scale developments, from both the public and private sector. A qualitative approach was used which combines these interviews with documentation and biographical information, both publicly available and from private narratives, to understand the international experience of the individuals and how they sought to challenge and adapt to global-local dynamics in their respective projects. Participants were recruited based on experience, using a reputational and network orientated approach to sampling. This was part of a deliberate attempt to cover as many components of the development process as possible. For each site, the development manager, lead consultants and planning permission documentation guided the selection process, helping to highlight the multiplicity of companies involved. Variety was included to address the heterogeneity of perspectives and strategies used at various stages of development. A range of roles within each of the main development companies was also included, to ensure the diversity of insider perspectives was included. This 
required speaking to people who worked in different geographies, including the Middle-East, South-East Asia, Southern Africa and Western Europe.

The interviews were conducted between September 2016 and August 2017, were semi-structured and typically lasted around an hour. They focused on the early stages of the development process, especially the period leading up to planning permission application. Within this there were four broad themes addressed: (1) day to day interactions and how these were shaped by the different nationalities and past experiences of individuals, (2) origin of ideas, (3) global experiences and (4) rationale for decision-making. Using these as guides, moments of conflict and integration were focused on to analyse the specific strategies adopted.

This paper uses two cases: Modderfontein in north-east Johannesburg and London's Royal Docks. These sites were both historically significant strategic areas within their respective cities, the Docks was the centre of the British Empire and in many ways the historical successes of London as a global city can be attributed to it. Modderfontein was home to an explosives factory which enabled Johannesburg's mining to take place; without these sites neither city would have the global position they occupy today. That is not to diminish their current strategic importance though, both sites sit on the development of new train-lines (Gautrain in Johannesburg and CrossRail in London), they are located near airports and have extensive road networks. The Docks is part of London's eastward shift and hopes to match its neighbour Canary Wharf, whilst Modderfontein is another example of the large new cities which have come to dominate Johannesburg's, and many African cities, periphery over the last few decades (Watson, 2014). Their strategic significance is something their respective local authorities are keen to capitalise on and as such they have both received extensive attention from government, investors and the media.

Modderfontein is a 1,600 ha green-field site in north-east Johannesburg previously owned by a local land developer, Heartland, who attempted to develop the site for twenty years. The development which occurred was relatively piecemeal, township plans across the site which lacked a true overarching vision, in this respect Heartland were 'more land developers than property developers' (JBG_Developer, 2017). The company was purchased in 2012 by Zendai, a Shanghai developer who wanted to build 'the Manhattan of Africa'. The development was announced by provincial government whilst on a tour of China, although they have no legal remit over the site or its plans and at the same time, Zendai announced an 80billion ZAR pot to fund the development which attracted calls from consultants across the globe who wanted a chance to be involved (JBG_Planner, 2017). In the face of this political buzz and the excitement of new investors, the local team wanted to capitalise on the opportunity to engage with an international team. In 2015 a 
'global' team, largely based in London, were hired to produce a masterplan, working with local stakeholders in 4 large group meetings which included former Heartland employees, consultants, politicians; the Chinese owners; and the City of Johannesburg. Off the back of these participatory forums, they created a masterplan which hoped to secure planning permission.

In contrast to the small scale development which occurred in Modderfontein in the lead up to the masterplan creation, London's Royal Docks have been in a constant state of regeneration since the Docks closed thirty years ago but very little has actually happened. The land is currently owned by the mayor's office (the GLA), and in 2012 they partnered with developers on a number of major plots. Development agreements were made with ABP, a Chinese developer, for the Royal Albert Docks where they hope to build an Asian business park. Just down the water, Silvertown Quays' rights were acquired by a London-based partnership 'The Silvertown Partnership'. Since 2012, both developers have hired assorted master-planners, engineers and consultants, mostly from 'global teams' with London headquarters. Across the sites there is overlap in consulting firms, and even in individuals within these firms, illustrating the extent to which these sites are comparable and inter-connected.

\subsection{The importance of on-boarding local political actors}

The developer cannot be simplified to just a single person or even a single organisation, a wide range of consultants are involved in decisions developers make (Robin, this issue). Within this, in the case of Modderfontein and the Royal Docks, international organisations had very specific roles that supported the overall development strategy, each providing relationships or information required to advance the plan through the planning permission process. For example, town planning consultants were used in both cases to ensure masterplans were made in line with local, regional and national planning objectives; whilst engineers were used for transport planning development in Johannesburg and heritage specialists worked in London. The people working on both sites' teams came from other places, for example Dutch landscape architects advised in Silvertown and London based but Middle East working environmentalists consulted in Modderfontein. Whilst these individuals had a wide variety of experiences which naturally informed their understandings of the specific problems or objectives at hand, the companies they worked for often positioned themselves, or the team, as 'global' or beyond a geographically circumscribed place. The success of these 'global' teams was highly contingent on their ability to locally embed themselves such that they were able to recognise, confront and deal with local politics, planning and people effectively. This required specific strategies and the approach varied depending on the people involved. 
In Modderfontein, once the Chinese developer announced their vision via a fan-fared media release within South Africa, the developer's commercial team were inundated with large firms wanting to "get a slice of the 80billion ZAR pie" (JBG_Planner, 2017). The developer, Zendai SA, then selected a deliberately 'global' team with Atkins as their lead consultants for the masterplanning exercise. This decision to hire Atkins over local teams was based on the form of their pitch: they submitted a video rather than a document from which the decision-maker in Zendai inferred they would bring new ideas and new "outside ways of thinking" (JBG_Director, 2017). At this point Atkins took the lead in co-ordinating efforts, and whilst contracts were drawn up between the developer and each consultancy firm, it was widely accepted that the Atkins' team lead was in charge. Atkins in turn hired further 'global' teams including Colliers International's 'Destination Team' and an Arup team - both of these straddled their London and Johannesburg offices. It was anticipated that those from Johannesburg would provide the necessary local knowledge, whilst those from elsewhere would bring fresh ideas and transplant their experiences from other megaprojects to this site. In this respect, Atkins immediately acknowledged the importance of having some local presence. The three teams worked closely during the masterplanning process, with those based in London acting as almost intermediaries between offices in Johannesburg and Atkins. They were co-ordinated by the lead at Atkins whose actions in many ways resembled the characteristics seen in previous analysis of the developer: she found a way to align the various consultant's perspectives, worked closely with Zendai teams and attempted to manoeuvre within the planning authority, Johannesburg City. What is important to recognise is that the teams were deliberately global - they were not London teams but rather people who had extensive experience working on large scale projects in various cities across the world. Whilst they all recognised that a large bulk of their work is done in the UK because of the nature of their firm's HQ and its location, as teams their work is done across America, Europe, Asia and Africa.

Throughout 2015 Atkins hosted 'stakeholder workshops' designed to bring together different voices on the development, and they invited anyone who had an interest in the site (JBG_Consultant 2017) - including those from Heartland (then Zendai SA), new Chinese team members of Zendai SA, former consultants from Heartland's land development phase, teams from the delivery arms of Johannesburg City (the road and development authorities), 'experts' in various planning disciplines from across the globe, the city government, the provincial government and local academics. For those working for the developer these were seen as vital windows in to the local culture, as one consultant recalled:

"[The workshops] are particularly useful in terms of people imparting the local knowledge. You always get them in those workshops, people who do understand the area really really 
well. Better than you could possible know yourself - they've lived their all their lives, they know the situation." (JBG_Consultant, 2017)

The workshops were split into small working groups where everyone had the chance to have their voice heard (JBG_Consultant, 2017) and then report back to the whole group. They aimed to "onboard the City" who had legislative power (JBG_Developers, 2017) by presenting various perspectives and showing how they aligned with the city's wider goals. However, they were seen to be "relatively one-sided" (JBG_Architect, 2017); less about participatory approaches and more about directing people towards a pre-determined Atkins led goal of a specific masterplan (JBG_Planner, 2017). In addition, Atkins hosted meetings between the developers and consultants who had previously worked on the site in an attempt to understand their ideas and were they came from (JBG_Planner, 2017). These meetings were again perceived by the ex-consultants as less about learning from locals and more about window-dressing the masterplanning exercise so it looked like local views were included in the process.

Between each of the larger stakeholder meetings the Colliers, Arup and Atkins teams worked closely on the iterative process of document formation - putting together reports which were sent out to all the attendees and acted as the primary means of communication between the City and the developer during this time. The documents were presented on behalf of the developer but unlike examples from elsewhere, the lead consultant represented the developer in most circles of communication and was perceived to be the key co-ordinating force in the project. The reports were "relatively weak" (JBG_Official, 2017), lacking specifics about how the plan was developing, instead they presented quotes from various attendees. In these moments the global team showed their lack of local awareness, these documents mis-read local politics. The provincial government officials were quoted, albeit out of context (JBG_Official, 2017) in a way that showed how Atkins misunderstood the relationship between the City and Province - that the City "hated that" (JBG_Official, 2017). Legislative authority over planning decisions in Johannesburg lies with the City, whilst the Gauteng Provincial government looks to be a 'higher' level than the city to an outsider, years of contest around who has the authority to grant strategic planning decisions resulted in a court ruling that the power lies with the City. This was totally ignored by Atkins who considered the support of the provincial government and its Premier as vitally important. Further to this, the cultural differences meant the City and Atkins clashed as members of the City's planning team felt they were patronised (JBG_Official, 2017) and looked-down on. In this respect Atkins demonstrated their incapacity to navigate local political tensions and consequentially off-boarded the city rather than onboarded them. 
In strong contrast, the example of the Royal Docks show how developers and their consultants can be politically effective by engaging across the public and private sectors and hiring locally recognised firms. The London Development Agency (LDA), a public sector body who was charged with controlling the docks and encouraging development in 2012, courted ABP and their CEO Mr Xi. The two organisations had a shared understanding about what would happen on the site and as such the public sector already supported ABP's plans, although it's worth recognising that the LDA were not the planning authority who granted planning permission. Utilising this relationship, to facilitate communication and actions on a local level, ABP sought advice from the LDA on how best to proceed. The Director of Land and Development at the LDA had experience working with another Chinese investor who brought a huge site in West London, he used knowledge gained there about the differences between the UK and China's development culture to navigate tensions which might arise during the early stages of rights acquisition and land assembly. He was able to "bridge the gap" between the developer and the local market, and nudge them towards hiring the most suitable local partners (LDN_Official, 2016). ABP then began their work by hiring local specialists, consultants, who worked to embed the wider development processes in local mechanisms.

What distinguishes this from the Johannesburg example is how the Chinese company in both cases sought to find a voice who would work well with the state, in Johannesburg this was done by spending vast quantities of capital on an global team who had experience and an international reputation. In contrast, in London, the firm was better advised about the nuances of the local system and as such hired firms with deliberately London based experience, especially the ability to navigate local political tensions. These examples show how important the local authority can be, it's about making sure the developers and those with authority are on the 'same page' (LDN_Official 2016; Fainstein, 2001). A mutual understanding about what might happen in the site, on a high abstract level, can help circumvent any issues later on since when you get the politics wrong, “you're just ruffling feathers. Rubbing hair backwards” (JBG_Architect, 2017).

\subsection{It's not who you hire, but where you hire}

During the Modderfontein masterplanning exercise Atkins led a team of consultants who worked alongside a secondary consultant team who were advising on the specifics of the central business district in the site, and the developers themselves. During this process the Atkins' team isolated these other private sector actors, both internal to the masterplan team and those working on other parts of the project. Individuals from the developer side, whose focus was the masterplan, perceived the action of Atkins to be a "marketing exercise" (JBG_Planner, 2017), rather than something which embodied the extensive knowledge the developer has of the site. At the same time, 
consultants who had worked - or were working - on other parts of the site felt "isolated" from the proceedings (JBG_Planner, 2017) and that they were not valued (JBG_Architect, 2017). As one of the local consultants noted, the Atkins plan largely ignored the local nuanced understanding of cultural norms which needed to be included in design, such as understandings about what security needed to be included, offered by local teams:

"The UK guys were saying there are other ways you can deal with security- you can do a bit of landscaping - have you guys ever been to SA? Like a burglar is not going to see a bird and be like I can't get in there- he's just going to walk over and through the tree. A bit of landscaping and trees for security- you guys just haven't got a clue." (JBG_Engineer, 2017)

Throughout the masterplanning exercise, a secondary team of largely Johannesburg (or Gauteng) based companies (Green Inc., DHK Architects, Aurecon and BlueGreen) was working on the specifics of what would become the 'CBD' of the site which was meant to slot in to the plan made by Atkins with a more detailed analysis of the focus of the development. This offered a chance for the Atkins team to closely align themselves to a four company team who each had extensive experience in Johannesburg. However, the opportunity was not seized and instead this smaller team felt ignored which undermined Zendai's efforts to create a cohesive plan which operated strategically but had specifics ready to go for the most important areas.

In the docks the developers leveraged their experiences working closely with the public sector and on the advice of the LDA employed local experts. In particular, ABP partnered with Stanhope, a long-term London player in the development world, and hired Farrells who have both a Hong Kong and London office as their lead architects (LDN_Architect, 2017). They also worked with specialist consultants who seek to bridge the gap between Chinese investors or firms, and London. The result was a web of consultants who were largely based in London and who provided a perceived 'legitimacy' to the project. In this way ABP were able to gain entry to the "club" of London's real estate market (LDN_Official, 2016) which in turn enabled them to get wider support for their project.

Crucially, the hiring of local firms and the wide range of London based consultants they worked with did not mean they did not hire non-London companies for other roles, instead they were able to find a balance which reflected the necessity of the sites. Whilst investors primarily came from China, since money from elsewhere is normally needed to support large projects in London (LDN_Developer, 2017); the firms picked from London often had experience in China or Asia (Savills, 2013). As one consultant who works on advising Chinese developers when they arrive in London 
explained to me: "I will be a very good example for you - I used to work for a developer in China- I was part of developer [laughs] and then I came here to do my Masters degree in Reading- real estate investment" (LDN_Consultant, 2017). For him, his past experience in a development arm was vital, but it's his knowledge from informal interactions and friendships acquired during his British studies which enable him to be an effective intermediary and assist Chinese firms.

ABP demonstrated an ability to read and navigate locally contingent processes and reacted accordingly, hiring local specialists to provide legitimacy and knowledge of the city and ensure they were able to operate effectively and secure planning permission. Silvertown Quays shows this too, they found a balance between investors from elsewhere, locally reputable consultants and specialists from other countries. They hired a range of consultants based on the specific needs of the site and in these cases the individuals and firms were picked based on trust and reputation (LDN_Manager, 2017). Further to this, when firms not primarily based in London were hired the importance of face to face contact was emphasised as a means of bridging the knowledge gap, as one of the developers from London explained the impact of the physical location of consultants:

"I mean West8 [based in the Netherlands] are great, they understand London, they understand the UK market. They work very closely with people like Fletcher Priest, theres a happy marriage value there - the downside of perhaps work with an architect from Japan or Chile you're not getting face-time" (LDN_Developer, 2017)

The hiring of local consultants and pairing with developers from the city can be hugely influential in getting planning permission. It is not enough to act entrepreneurially with the local state or planning authority, the developers when from elsewhere must instead leverage their social capital to hire the most appropriate team for each job and often this requires trading global experience with local expertise. The Modderfontein site now sits in limbo, the masterplan has not been approved by the City. The officials who received it in the City of Johannesburg do not see their voice, as expressed in the participatory stakeholder meetings, reflected in the documents produced. Locals who had worked on previous iterations of the plan which pre-dated Atkins involvement see very little difference between their's and the new one (JBG_Planner, 2017) and feel the global team were inadequate. Teams working on other parts of the plan feel isolated by the experience and like their knowledge was undervalued by a developer desperate to flex their financial muscles (JBG_Developers, 2017). Zendai hired a 'world class' consultant to impress the city and bring ideas from elsewhere, but it was the wrong team and the lack of humility and inability to embed themselves in local cultures meant two years later the site sits as a white elephant and Zendai are no longer inter- 
ested (or financially able) to continue development. Modderfontein then shows the way potential is lost if you hire people who do not know the best way to operate locally.

The difference between the two sites highlights the importance of understanding the locally embedded nature of urban development. Whilst in Modderfontein the developer sought to provide legitimacy by hiring the 'world's best', the failures of the global teams to effectively engage with local politics and understandings means the City is only now, 2 years later, reluctantly putting the plan to council for approval. In contrast, in London the developers picked their consultants based on the best options locally and used the people around them to ensure their plans were processes as quickly as possible because legitimacy was valued or perceived in a different way. The relative success of the projects cannot be simply attributed to the different approaches of the consultants used, nor can the failure of the consultants only be attributed to their organisations. Rather, these examples highlight the importance of locally contextualised information for developers and the relevance of understanding how developers learn how to operate in a place.

\subsection{Becoming part of the club}

Throughout the interview process, in both Johannesburg and London, the idea of the city being a small club of real estate firms was consistently returned to. Those working in the private sector repeatedly referred to its close knit community nature and the importance of reputation, trust and knowing the right people. When developers come from another location, it is therefore necessary to find a way to integrate into this club, often learning from consultants hired or partners, as addressed in the previous two sections. To become part of the club developers must take their role as co-ordinators to a new level and integrate the various members of the developer team, and then align these with external relationships such that a culturally sensitive management approach brings new members to the city's system and forges relationships between them and established players. The cases of Modderfontein and the Royal Docks illustrate how attempts to do this require strong management within the company and for external leads to make deliberate efforts to overcome any cultural differences.

When Zendai purchased Heartland in 2012, the media paid the deal and the site's proposals a lot of attention as it spoke to the on-going discussion around China's investment in the continent of Africa and the roles of Chinese spaces in Johannesburg (cf. Dittgen, 2017). The Chinese developer brought over its own team, primarily consisting of people who worked on the buy-out deal, but maintained the contracts of former Heartland employees at a guaranteed above market rate. To complement these two teams they also made a deliberate effort to hire a number of second-gener- 
ation Chinese-South Africans to work in the office and straddle the cultural and language divide. However, the strong ties internal to Zendai which mimicked the 'club' nature of real estate in the city more broadly meant the Chinese-South Africans were often grouped with the workers who came from Shanghai and there became a strong sense of 'us and them' which divided the office. The company tried further schemes to overcome this, especially issues around language which was perceived by consultants, the City and the white workers from Heartland to be a significant issue which limited the Chinese workers' capacity to be effective. This was done by providing documents and signs in both languages so no one felt isolated and offering all in the office language lessons, English for those from China and Mandarin for the former Heartland employees.

Language lessons happened twice a week but very few people continued beyond the first year. As one of the developer team explained the everyday processes and informal interactions were very divided in the office: "With one another they [the Chinese Zendai workers] do speak Mandarinyou'll never find one that speaks English to Chinese. The Chinese they don't speak English" (JBG_Developer, 2017). As this quote suggests, language and culture remained an internal barrier which meant teams were often working in parallel rather than together, and as such each felt pressure from the other. The attempts by Zendai were largely seen as too little, too late by people in the office (JBG_Developer, 2017) and the Chinese workers who relocated to South Africa remained 'outsiders' unable to penetrate local or industry-specific cultures and engage effectively (JBG_Manager, 2017).

This division in the workers translated up the hierarchy and meant Zendai effectively operated as two separate companies, side by side (JBG_Manager, 2017), which in turn filtered through in their interaction with the wider consultant team who failed to grasp what the masterplan was seeking to achieve. As one consultant's recollection of the plan indicates below, the principles of the masterplan were largely perceived to be 'objective' by the consultants but for many people on the site it was unclear where the direction came from and what Zendai was seeking to build, in terms of a model:

"Let's call it the Chinese model, would have been coming out the other design more. It actually didn't. It was never much a UK design, let's call it a UK design instead of anything else. It wasn't actually SA design as well. I must say, its quite horrific these days- you probably know about the gated communities you've got here - everything has been built like that. What Margot and the team was trying to do was town planning principles was create little villages around intersections" (JBG_Consultant, 2017) 
From the perspective of many working on the site, the development manager should have taken charge, driven forward a cohesive internal team with a clear vision which would have afforded them better relationships internally and externally. Instead, Zendai were unable to unite their workers which resulted in a fractured workplace, divided by race and culture which was unable to operate effectively because neither group shared their respective knowledge or skill set as best as they could. Consequently, the first stage of becoming part of the club - becoming part of the firm - did not happen for many of the Chinese workers.

The second stage of becoming part of the club, integrating the new firm into existing networks in Johannesburg's real estate sector, was also limited by the lack of leadership from the developer. As one of the Johannesburg consultants explained: "They [Zendai] weren't really dictating much, look I think it was completely new to everyone. To themselves as well. Zendai didn't know the South African market" (JBG_Consultant, 2017). The dominance of a few large firms and the sense of community which characterised both cities' real estate sectors means developers need to understand what is happening and the internal politics. In London, the LDA effectively bridged the knowledge gap and ensured that, despite a radical vision for the site, ABP were able to begin the process in good faith with local actors - because they partnered with them, as addressed above, and in doing so were considered to have "joined the club" (LDN_Official, 2016). In Modderfontein, the story was different, since the developer decided to break from their relationships with many of their local consultancy teams and instead use a 'global' team with Atkins, the Atkins lead needed to find a way to become part of the Johannesburg system. This was especially true because of the internal dynamics of Zendai where miscommunication and misunderstandings between the Chinese and South African arms of the company meant it lacked strong internal direction and so the consultants were relied on more heavily. In this case, weak vision on the part of the developer undermined their efforts to integrate locally and therefore prevented their project from taking off.

Looking across the two sites therefore highlights the dynamism associated with developers and their ability to co-ordinate the necessary forces within the private sector becomes even more vital when international actors are involved. They become the nexus of an even more complicated network of social and physical arrangements and must leverage their soft power skills to navigate tensions within their own corporations, with external global consultants and to on-board the public sector, if they are to proceed with the development. Key individuals within the developer must respect the complexity of the local environment and find a way to bridge any gaps which arise, culturally or in knowledge base. When they utilise the people and possibilities around them, as ABP did in London, they are able to move forward. In Modderfontein, the lack of vision from the development manager and its consequential divided development team combined with an ineffective 
expensive 'global' consultancy isolated key stakeholders and meant they did not become part of the club.

\section{Concluding Discussion: Understanding what it means to be 'Global'}

The cases of Modderfontein and the Royal Docks both speak to the importance of locally embedded understandings of the urban and the way in which producing plans and gaining the necessary permissions is predicated on a deep engagement with local actors and situations. They also speak to the way ideas can travel across the globe with distinctly different manifestations (Stone, 2004; Ward, 2006; McCann, 2008; Wood, 2014; Rapopart and Hult, 2017) and the specific role of developers in facilitating this. The success of the developers in London can be attributed not to an inherently easier to understand planning context but rather to the way they hired locals, partnered with London based developers and utilised links and cultural understandings of the public sector. In sharp contrast, Zendai's actions illustrate how wrong things can go when global consultants attempt to work in new places without full consideration of local contexts.

For both Chinese developers, who were new to the cities they were working in, it was essential they understood the political context they were entering (Fainstein, 2001) and whilst for one this became a priority which in turn heavily influenced their ability to further integrate in the city, for the other hiring a global team to do it on their behalf further detached them from the location. This is suggestive of the different ways of embodying 'global', 'international' and 'transnational' as corporate labels, since what is means to be global and how this varies place to place, and the way in which the idea of being global was communicated was significantly different in the two locations. In the London context the local consultants hired often worked abroad, but distinctly mark themselves as London orientated teams. Their offices are headquartered in London and the majority of the firm's work is in the city, but they are able to bring ideas from other locations as and when needed. In contrast, similar firms were hired for the Johannesburg project but rather than hiring the local office they hired a global team. For example, whilst Colliers International has offices across the globe including in Johannesburg, Zendai deliberately hired the 'Destination Team' who consider themselves separate since they are "financed differently" (JBG_Consultant, 2017) and act "more as management consultants" (comparable to business orientated firms like McKinsey\&Co, Bain or BCG who primarily do not work in urban settings) than other members of their company (JBG_Consultant, 2017).

Likewise, contrary to the rhetoric around hiring a 'London' firm which circulated Johannesburg media, the Atkins team was a 'global' team who specialise in large projects rather than a particular 
location. The strength of such approaches is meant to be the ability to bring ideas from all over the globe using expertise developed in another situation to help implement new ideas in other cities (McCann, 2008), but the reality was a mismatch between the suggested ideas and the applicability to local contexts. The usefulness of the ideas from elsewhere was commented on throughout my research, with different consultants or stakeholders remarking on various components of the Atkins plan which they believed to be inappropriate for Modderfontein, from the suggestion of a theme park through to understandings undervaluing Johannesburg's car orientated approach to living. This inability to understand local contexts was frequently attributed to the nature of the teams: they circulate ideas around the world but fail to stay for implementation and therefore do not see how ideas fit or do not fit in each location. In this respect they were perceived as incapable of recognising that the entanglement of ideas and people which go in to making an urban environment is not a-spatial (Halbert and Attuyer, 2016); it is inherently transcalar. As financial networks have been shown to need elsewhere, here the ideas behind urban projects require a re-intermediation (Halbert and Rouanet, 2014) which unfolds in distinctly localised places (Halbert and Attuyer, 2016).

In highly internationalised urban environments developers must used their entrepreneurial skills to navigate the global-local balance and learn to operate effectively in their new work environment (Weinstein, 2014). The cases of both Modderfontein and the Royal Docks highlight the necessity of embedding themselves in local networks and the means by which this can be achieved. Putting the sites in conversation with one another shows the relative importance of engaging with individuals on a personal level, those who have a reputation for delivery locally, rather than globally important firms. Hiring the 'best of the best' does not guarantee getting planning permission if the firm hired lacks the capacity to navigate local politics (Fainstein, 2001), both internal to the private sector and with the state. The developer then is charged, in both places, with finding vehicles or mechanisms through which their global approaches can become locally entrenched - they must respect customs and cultures. This conclusion invites us to think about the developer's entrepreneurial skills as something which goes beyond straddling the public-private sector and must be capable of navigating a wider range of issues. In this respect they can be seen as a translator or a bridge, as well as a co-ordinator; they embody the transcalar nature of development.

On a theoretical level this comparison speaks to questions around how urban theory travels and the roles different agents play in the process. As work on policy movement has shown, the route and trajectory policy transfers happen in are inseparable, and the way they manifest in their new locations is inevitably shaped by experiences elsewhere (Ward, 2006; Robinson, 2015). The vocabulary we have for understanding how policies change and morph during processes of transformation can be inadequate (Robinson, 2015), and this example of ideas moving adds to this issue 
further. Drawing on Allen and Cochrane (2007), Robinson encourages us to stretch our analytical frameworks to more effectively think about how topological discussions can be applied to the movement of urban theory (Allen, 2016). The comparison of Modderfontein and the Royal Docks then speaks to the need to understand it "through both topographical and topological spatial imaginations" (Robinson, 2015: p. 833). Such an approach challenges us think about how ideas change over space and time, simultaneously remaining the same yet changing as the power of the idea is transformed in its new reach (Allen, 2016). Agents involved in this process therefore need to be better understood to question how their respective strategies or approaches dictate the manifestation - the success or failure - of their actions and ultimately shape the development of new urban environments.

Funding: This research did not receive any specific grant from funding agencies in the public, commercial, or not-for-profit sectors.

Declarations of interest: none 


\section{Bibliography}

Aalbers, M. B. (2017). The Variegated Financialization of Housing. International Journal of Urban and Regional Research, 41(4), 542-554. doi:10.1111/1468-2427.12522

Allen, J. (2016). Topologies of power : beyond territory and networks: London : Routledge.

Allen, J., \& Cochrane, A. (2007). Beyond the Territorial Fix: Regional Assemblages, Politics and Power. Regional Studies, 41(9), 1161-1175. doi:10.1080/00343400701543348

Bentick, B. L., \& Pogue, T. F. (1988). The Impact on Development Timing of Property and Profit Taxation. Land Economics, 64(4), 317-324. doi:10.2307/3146304

Bok, R., \& Coe, N. M. (2017). Geographies of policy knowledge: The state and corporate dimensions of contemporary policy mobilities. Cities, 63, 51-57. doi:10.1016/j.cities.2017.01.001

Brown, P. H. a. (2015). How real estate developers think : design, profits, and community<span class="frbrsuppress"> /\&nbsp;Peter Hendee Brown. Philadelphia: Philadelphia : University of Pennsylvania Press.

Christophers, B. (2015). The limits to financialization. Dialogues in Human Geography, 5(2), 183-200. doi:10.1177/2043820615588153

Coiacetto, E. J. (2000). Places Shape Place Shapers? Real Estate Developers' Outlooks Concerning Community, Planning and Development Differ between Places. Planning Practice \& Research, 15(4), 353-374. doi:10.1080/02697450020018790

Crosby, N., \& Henneberry, J. (2016). Financialisation, the valuation of investment property and the urban built environment in the UK. Urban Studies, 53(7), 1424-1441. doi: 10.1177/0042098015583229

Dittgen, R. (2017). Features of Modernity, Development and 'Orientalism': Reading Johannesburg through its ' Chinese' Urban Spaces. Journal of Southern African Studies, 43(5). doi: 10.1080/03057070.2017.1370306

Ellson, R., \& Roberts, B. (1983). RESIDENTIAL LAND DEVELOPMENT UNDER UNCERTAINTY*. Journal of Regional Science, 23(3), 309-321. doi:10.1111/j.1467-9787.1983.tb00992.x

Fainstein, S. S. (2001). The city builders : property development in New York and London, 1980-2000 (2nd ed., rev. ed.). Lawrence: Lawrence : University Press of Kansas.

Gore, T., \& Nicholson, D. (1991). Models of the Land-Development Process: A Critical Review. Environment and Planning A, 23(5), 705-730. doi:10.1068/a230705

Guy, S., \& Harris, R. (1997). Property in a Global- risk Society: Towards Marketing Research in the Office Sector. Urban Studies, 34(1), 125-140. doi:10.1080/0042098976302

Guy, S., \& Henneberry, J. (2000). Understanding Urban Development Processes: Integrating the Economic and the Social in Property Research. Urban Studies, 37(13), 2399-2416. 
Halbert, L., \& Attuyer, K. (2016). Introduction: The financialisation of urban production: Conditions, mediations and transformations. Urban Studies, 53(7), 1347-1361. doi: $10.1177 / 0042098016635420$

Halbert, L., Attuyer, K., \& Sanfelici, D. (2016). Financial markets, developers and the geographies of housing in Brazil: A supply-side account. Urban Studies, 53(7), 1465-1485. doi: 10.1177/0042098015590981

Halbert, L., \& Rouanet, H. (2014). Filtering Risk Away: Global Finance Capital, Transcalar Territorial Networks and the (Un)Making of City-Regions: An Analysis of Business Property Development in Bangalore, India. Regional Studies, 48(3), 471-484. doi:10.1080/00343404.2013.779658

Halbert, L., \& Rutherford, J. (2010). Flow-place : reflections on cities, communication and urban production processes. In (Vol. 5). France: GaWC Research Bulletin.

Healey, P. (1991). Models of the development process: A review. Journal of Property Research, 8(3), 219-238. doi:10.1080/09599919108724039

Healey, P. (2013). Circuits of Knowledge and Techniques: The Transnational Flow of Planning Ideas and Practices. International Journal of Urban and Regional Research, 37(5), 1510-1526. doi: 10.1111/1468-2427.12044

Henderson, V., \& Mitra, A. (1996). The new urban landscape: Developers and edge cities. Regional Science and Urban Economics, 26(6), 613-643. doi:10.1016/S0166-0462(96)02136-9

Larner, W. (2003). Neoliberalism? Environment and Planning D: Society and Space, 21: 509-12. (Vol. 21, pp. 509-512).

Larner, W., \& Laurie, N. (2010). Travelling technocrats, embodied knowledges: Globalising privatisation in telecoms and water. Geoforum, 41(2), 218-226. doi:10.1016/j.geoforum.2009.11.005 Magalheas, d. (2008). Global Players and the Re- Shaping of Local Property Markets: Global Pressures and Local Reactions. Oxford, UK: Oxford, UK: Blackwell Science Ltd.

Massey, D. B. For space.

McCann, E. (2011). Urban Policy Mobilities and Global Circuits of Knowledge: Toward a Research Agenda. Annals of the Association of American Geographers, 101(1), 107-130. doi: 10.1080/00045608.2010.520219

McCann, E. J. (2008). Expertise, Truth, and Urban Policy Mobilities: Global Circuits of Knowledge in the Development of Vancouver, Canada's 'four Pillar' Drug Strategy. Environment and Planning A, 40(4), 885-904. doi:10.1068/a38456

Prince, R. (2014). Consultants and the global assemblage of culture and creativity. Transactions of the Institute of British Geographers, 39(1), 90-101. doi:10.1111/tran.12012

Prince, R. (2017). Local or global policy? Thinking about policy mobility with assemblage and topology. Area, 49(3), 335-341. doi:10.1111/area.12319 
Rapoport, E., \& Hult, A. (2017). The travelling business of sustainable urbanism: International consultants as norm-setters. Environment and Planning A, 49(8), 1779-1796. doi: $10.1177 / 0308518 \times 16686069$

Robin, E., \& Brill, F. (2018). The global politics of an urban age: creating 'cities for all' in the age of financialisation. Palgrave Communications, 4(1), 3. doi:10.1057/s41599-017-0056-6

Robinson, J. (2006). Ordinary cities between modernity and development. London ; New York London: London ; New York : Routledge.

Robinson, J. (2011). Cities in a World of Cities: The Comparative Gesture. International Journal of Urban and Regional Research, 35(1), 1.

Robinson, J. (2015). 'Arriving At' Urban Policies: The Topological Spaces of Urban Policy Mobility. International Journal of Urban and Regional Research, 39(4), 831-834. doi: 10.1111/1468-2427.12255

Robinson, J. (2016). Thinking cities through elsewhere. 40(1), 3-29. doi: $10.1177 / 0309132515598025$

Roy, A., \& Ong, A. (2011). Worlding Cities : Asian Experiments and the Art of Being Global. Hoboken: Hoboken: Wiley.

Stone, D. (2004). Transfer agents and global networks in the 'transnationalization' of policy. Journal of European Public Policy, 11(3), 545-566. doi:10.1080/13501760410001694291

Watson, V. (2014). African urban fantasies: dreams or nightmares? Environment \& Urbanization, 26(1), 215-231. doi:10.1177/0956247813513705

Weinstein, L. (2014). 'One- Man Handled': Fragmented Power and Political Entrepreneurship in Globalizing M umbai. International Journal of Urban and Regional Research, 38(1), 14-35. doi: 10.1111/1468-2427.12040

Wood, A. (2004). The Scalar Transformation of the U.S. Commercial Property-Development Industry: A Cautionary Note on the Limits of Globalization. Economic Geography, 80(2), 119-140. doi: 10.1111/j.1944-8287.2004.tb00304.x

Wood, A. (2014). Learning through Policy Tourism: Circulating Bus Rapid Transit from South America to South Africa. Environment and Planning A, 46(11), 2654-2669. doi:10.1068/a140016p 